ARGONNE NATIONAL LABORATORY

9700 South Cass Avenue

Argonne, Illinois 60439

\title{
PARADIGM FOR EXPERT DISPLAY SYSTEMS \\ IN NUCLEAR PLANT AND ELSEWHERE
}

\author{
J. R. Gabriel
}

Mathematics and Computer Science Division

Technical Memorandum No. 64

February 1986

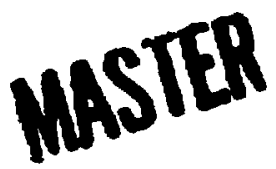

\section{DISCLAIMER}

\begin{abstract}
This report was prepared as an account of work sponsored by an agency of the United States Government. Neither the United Stales Government nor any agency thereof, nor any of their employees, makes any warranty, express or impliod, or assumes any legal liability or responsibility for the accuracy, compteteness, or usefulness of any information, apparatus, product, or process dischosed, or represents that its use woukd not infringe privately owned rights. Reference herein to any specific commercial product, process, or service by trade name, trademart, manufacturer, or otherwise does not necessarily constitute or imply its endorement, recommendation, or favoring by the United States Government or any ageacy thereor. The views and opinions of authors expressed herein do not necessarily siate or reflect thowe of the United States Government or any agency thereof.
\end{abstract}




\title{
Paradigm for Expert Display Systems
}

\author{
in Nuclear Plant and Elsewhere*
}

\author{
J. R. Gabriel \\ Miathematics and Computer Science Division \\ Argonne National Laboratory
}

\section{Introduction}

Display of relevant data concerning plant operation has been a concern of the nuclear industry from its beginnings. Since the incident at Three Mile Island, this matter has had much careful scrutiny. L. Beltracchi, in particular, has originated a sequence of iniportant steps to improve the operator's ability to recognize plant states and their changes.

In the early 1980's, Beltracchi $(1983,1984)$ proposed a display based on the Rankine cycle for light water reactors. More recently, in an unpublished work (1986b), he descrited an excension that includes a small, rule-based system in the display pregram, drawing inferences about plant operation from sensor readings, and displaying those inferences on the Rankine di:olay.

Our paper examines Beltracchi's rule-based display from the perspective of knowledge bases. Earlier (Gabriel, 1983) we noted that analytical models of system behavior are just as much a knowledge base as are the rules of a conventional expert system. The problem of finding useful displays for a complex plant is discussed from this perspective. We then present a paradigm for developing designs with properties similar to those in Beltracchi's Rankine cycle display. Finally, to clarify the issue, we give a small example from an imaginary plant.

\section{Analytical Models of Physical Systems}

Engineered artifacts such as nuclear steam supply systems have analytical models. In their most fine-grained detail such models have thousands of state variables, so that the system state is represented by a point in a many-dimensional space.

\subsection{Static Displays}

For the most part, static displays have been used to represent sucii systems. The term "static display" here does not imply that the display does not change but rather, that the algorithm used to derive the display from plant sensors does not change.

The Safety State Vector (SSV) and the Safety Parameter Display System (SPDS) are examples of static displays. The SSV provides a discriminant between safe and unsafe operation; the SPDS produces a computer-generated display of the SSV. Because they are concerned with multiple variables and because a computer-generated CRT display is a two-dimensional object, both the SSV and the SPDS burden the plant operator with a significant task in filtering inferences from a display of a multidimensional space on a two-dimensional screen.

\subsection{Mental Models}

Useful mental models of plant are obtained by discarding two classes of variables. One class contains those variables essentially irrelevant at the level of detail being considered, i.e., "microscopic" as distinct from "macroscopic" state information. The other class comprises macroscopic variables

\footnotetext{
*Work supported in part by the Applied Mathematical Sciences subprognm of the Office of Energy Research, U.S.
} Department of Energy, under contract W-31-109-Eng-36. 
irrelevant to (not affecting) the future path of the current scenario. However, even after the irrelevant variables have been discarded (projected out), the state space is usually still quite complex.

\subsection{Rule-Based Display Algorithms}

In a meeting on the use of computers in piant operation, W. A. Woods (1980) pointed out the desiratility of having a rule-based expert system choose the most appropriate display out of several possibilities. Such an expert display system, if possible, would present the operator with enough information to run the plant, but not burden the operator with unnecessary choices about displays.

The first such display to be developed was Beltracchi's Rankine cycle display.

Beltracchi's display is a two-dimensional projection out of the state space, having a very large data transfer rate to an operator. In his papers and pending patent, Beloracchi develops that display and shows how it has unequivocal signatures for important loss-of-coolant events. These clear signatures allow an operator to resolve ambiguity about plant state and take necessary action quickly and reliably.

In more recent studies, Beltracchi (1986a) makes use of a small, rule-based system to augment the display and provide additional diagnostic information.

The possibility of such a useful iwo-dimensional display was not obvious at the outset, the display was difficult to discover, and two questions still remain. First, might other displays for other circumstances be possible having similar large, effective data communication rates to operators? Second, if they do exist, how might they be discovered?

\section{The Process of Meta Design}

The following suggests answers to the two questions posed at the end of Section 2.3.

1. Given some hypotheticai event leading to off-normal plant conditions, the first step is to examine a simulation model of the plant path in state space, and determine the smallest set of variables in the simulation able to show what has happened and what must be done to move the operating point back to a safe place.

Because people design plant and a human being has trouble considering many variables together, it is likely that there exists a set of perhaps less than six variables able to provide clear signatures for any particular event. If this is not true, a prima facie case arises for redesign, because it is unlikely that a human designer can have considered all possibilities from the initiator of a small excursion to unsafe conditions.

2. Once these variables have been identified, possible paths of the operating point through the projected space of these variable should be considered, and the viewpoints for two-dimensional projections (i.e., CRT displays) discriminating between various scenarios in the larger dimensional space should be determined.

If one projection suffices to discriminate between all important scenarios, then no further expertise is needed.

If, on the other hand, several points of view are needed, then (by hypothesis) these will show projections with different characteristics. In this case a computer program processing data from an actual incident should be able to examine the data from those perspectives and should display the most significant projection, together with a list of other projections in computed order of significance, to allow the operator to call them up if desired.

\section{More Complex Problems}

Eventually, automated techniques in plant design may lead to circumstances where more than a few sjgnificant variables are necessary to display relevant macroscopic plant state. Even then, however, there should be some set of projections and coordinate transformations able to distinguish between 
significantly different off-normal events, soon enough to stop undesirable trends, since significantly different events follow different paths in state space.

If this is not the case, then the plant design must have been such that small changes in state variables have large and unavoidable consequences. Such a situation will arise only if the plant is inherently unstable. Obviously, its absence should be a primary objective of design.

\section{A Sriall Example}

A small example about an imaginary plant follows, to help clarify the fundamental point made in this memorandum.

Consider a plant having a three-dimensional state space, whose normal operating point is $(0,0,0)$. The plant goes off-nomal by the following transitions:

$$
(0,0,0) \rightarrow(1,0,0) \quad(1,0,0) \rightarrow(0,1,0) \quad(0,1,0)->(0,0,1)
$$

The changes $0->1$ of state variables might be a cause-and-effect chain in three subsystems. A view along [001] would display the first two failures, but not the third; a view along [010] would miss the middle failure; and a view along [100] would fail to show the initiating event. One might display all three points of view on separate CRTs, but points on the paths would have to be time stamped if the order of events was to be determined.

A view along [111] would show the following motion on the CRT in the plane defined by $(2,-1,-$ $1)$ and $(0,1,-1)$ in the old coordinates:

$$
(0,0) \rightarrow(2,0) \quad(2,0)->(0, \text { sqrt }(3)) \quad(0, \operatorname{sqrt}(3)) \cdot>(0,-\operatorname{sqrt}(3)) .
$$

The three events are clearly shown. Note, however, that if an event

$$
(0,0,0) \rightarrow(1,1,1)
$$

is possible, it will be missed by the [111] projection. Therefore, in general, an intelligent software system should choose projections and display the one most likely to communicate the sequence of events to the operator.

In the small example shown, two displays might be provided: one normal to the approxinate plane of the most recent part of the system's path in state space, and the other a display of as many changes in direction of the path as possible. The first of these two provides as much detail as is obtainable concerning the current situation. The second, whose calculation is less well understood, should provide a continuous record of significant "bends" in the path since the initiating event.

\section{Acknowledgments}

1 owe a great deal to Leo Beltracchi for regular conversations about his research. Without the stimulus of that interaction, this aper could not have been written; and without the path he cut through the jungle of irrelevancies to develop his displays, I could never have followed with the inevitable semi formal theory. I hope my notes here complement Leo's pioneering efforts, making it easier for the nuclear industry to follow his example in developing displays truly able to show useful information.

I have had heip with this work from others besides Loo. Parts of the material presented evolved from a conversation with Dick Lindsay of EBR-II. Gail Pieper, our technical editor, has been of inestimable assistance in various drafts of the paper, helping me make sure I wrote what we bcth thought I meant; without her, this document would have been less clear and therefore less useful.

\section{References}

L. Beltracchi, 1983. "Iconic Display, Rankine Cycles, and Human Factors for Control Rooms of Nuclear Plant." IEEE Trans. Nuc. Sci., Vol. NS-20, no. 3. 
L. Beltracchi, 1984. "A Process/Engineered Safeguards Iconic Display." Symposium on New Techniques in Nuclear Plant Instrumentation and Control, Washington, D.C.

L. Beltracchi, 1986a. "The Heat Engine Cycle, The Heat Removal Cycle, and Ergonomics of the Control Room Displays." Presented at the International Topical Meeting on Advances in Human Factors in Nuclear Power Systems.

L. Beltracchi, 1986b. Private communication.

Gabriel, J. R., 1983. "Algorithms for Automated Diagnosis of Faults in Physical Plant." Argonne National Laboratory Report ANL-83-70.

W. A. Woods, 1980. Private communication at a seminar on Computer-Assisted Nuclear Plant Operation, Applied Mathematics Division and Reactor Analysis and Safety Division, Argonne National Laboratory. 